\title{
Role of Homocysteine in Diseases: A Review
}

Maryam Moradi Binabaj (MSc)

Biochemistry and Nutrition

Research Center, Faculty of

Medicine, Mashhad University of

Medical Sciences, Mashhad, Iran

Mojgan Nejabat (MSc)

Department of Medicinal

Chemistry, School of Pharmacy,

Mashhad University of Medical

Sciences, mashhad, Iran.

Hamidreza Joshaghani (PhD)

Department of Medical

Laboratory, Golestan University

of Medical Sciences, Gorgan, Iran

Corresponding author:

Hamidreza Joshaghani

Email:

hr_joshaghani@yahoo.com

Tel: +98-9111779909

Address: Department of

Paramedical Sciences, Golestan

University of Medical Sciences,

Gorgan, Iran

Received : 26 Sep 2014

Revised: 01 Dec 2014

Accepted: 06 Dec 2014

\section{ABSTRACT}

Cardiovascular disease (CVI) is one of the most important causes of mortality worldwide. Several risk factors have been proposed to be associated with CVID. The main risk factors include family history, smoking, hypertension, history of diabetes, hyperlipidemia and obesity. However, new factors have been recently proposed to be associated with CVID. These include blood homocysteine, fibrinogen, plasma factor VII activity, lipoprotein (a) and several other factors. Nowadays, the role of homocysteine in the development and exacerbation of several diseases has been demonstrated. Extensive studies have been performed on the role of homocysteine in diabetes, preeclampsia, depression, Alzheimer's disease and multiple sclerosis. Homocysteine level increases with age. Moreover, absorption of micronutrients, especially vitamin B12, decreases in old age that could cause a further increase in homocysteine level. On the other hand, elasticity of blood vessels decline with aging, and increased levels of homocysteine accelerate atherosclerosis. The sum of these processes highlights the role of homocysteine in the development and exacerbation of several diseases.

Keywords: Homocysteine, Cardiovascular Disease, Diabetes, Preeclampsia, Depression, Alzheimer's Disease. 


\section{INTRODUCTION}

Cardiovascular disease (CVD) is one of the most important causes of mortality worldwide (1). It is expected that CVD will remain as the most important cause of death (36\%) until 2020. It accounts for 17 million deaths per year, and one-fourth of the 40 million annual deaths in developing countries. CVD is also the most common cause of death in Iran (2). Many risk factors have been proposed to be associated with CVD. The main risk factors include family history, smoking, hypertension, history of diabetes, hyperlipidemia and obesity. However, new factors have been recently proposed and taken into consideration $(1,3)$. These include blood homocysteine, fibrinogen, plasma factor VII activity, lipoprotein (a) and several other factors (1). Although many studies are available on the impact of hyperhomocysteinemia on CVD, the adverse effects of this condition on development and exacerbation of diseases should not be ignored. This review has aimed to report the effects of homocysteine on the cardiovascular system, and the role of this amino acid in other diseases.

\section{MATERIAL AND METHODS}

The role of homocysteine in a particular disease was investigated considering each section. Articles published between 2000 and 2013 were searched on PubMed, Google Scholar and Iranmedex. Reviews, non-English and Persian papers, and non-full-text articles were excluded. Several articles were studied for each section, and articles related to the objectives of this review were selected and used.

\section{Metabolism of homocysteine}

Homocysteine is formed via trans-methylation of s-adenosylmethionine. It is then added to serine to form cystathionine (vitamin B6depented reaction) in a process called the transsulfuration pathway, leading to production of cysteine and alpha-ketobutyrate. Insufficient amounts of folate and vitamin B12 can increase blood homocysteine level (4). Defective homocysteine metabolism increases its plasma level. The defect could be genetic similar to cystathionine- $\beta$-synthase (CBS) deficiency and 5, 10methylenetetrahydrofolate reductase (MTHFR) or acquired similar to inadequate uptake of folate and vitamin B6/B12 that are cofactors for enzymes necessary for the homocysteine metabolism (5). In early reports in 1964, Mudd et al. showed that the accumulation of homocysteine in blood and urine is due to CBS deficiency (3). Normal homocysteine level ranges between 5 to 15 $\mu \mathrm{mol} / \mathrm{L}$, and hyperhomocysteinemia is classified as mild $(15-30 \mu \mathrm{mol} / \mathrm{L})$, moderate (30-100 $\mu \mathrm{mol} / \mathrm{L}$ ) and severe (more than 100 $\mu \mathrm{mol} / \mathrm{L}$ ) (6). According to some reports, 5$10 \%$ of individuals in a population have mild to moderate hyperhomocysteinemia (15-40 $\mu \mathrm{M}$ plasma homocysteine) (7). It is estimated that two thirds of hyperhomocysteinemia cases are due to vitamin B12, vitamin B6 and folate deficiency, while folate appears to be more important in this regard (8). Homozygous CBS subjects or individuals with hereditary defect of cobalamin metabolism have very high levels of homocysteine, and are often subjected to severe and premature atherosclerosis (9).

\section{Genetic disorders of the impaired homocysteine metabolism pathway}

cDNA of CBS, MTHFR, methionine synthase (MTR) and methionine synthase reductase (MTRR) were studied to assess the functional polymorphisms that affect folatehomocysteine metabolism. The most-studied variant is $677 \mathrm{C}>\mathrm{T}$ polymorphism (Ala222Val) in the MTHFR that causes a minor dysfunction in the enzyme. MTHFR 677TT genotype is associated with increased levels of total homocysteine, particularly in subjects with low folate levels. Other functional variants in the above enzymes include MTHFR 1298A > C (Glu429Ala), 2756A> G, MTR (Asp919Gly), CBS 844ins68 
and MTRR 66A > G (Ile22Met). Studies have shown that MTR 2756AA homozygotes have significantly higher total homocysteine levels compared to $2756 \mathrm{AG}$ and 2756GG pairs, while CBS844ins68 carriers have lower total homocysteine level than non-carriers, after receiving methionine. Moreover, MTRR 66AG homozygotes have higher homocysteine levels compared to heterozygotes 66AG and homozygotes 66AA $(10,11)$.

\section{Association of homocysteine with vascular damage}

Study of McCully showed that patients with CBS deficiency face more severe vascular damage compared to other enzymatic defects in the homocysteine metabolism pathway. The vascular damage could be due to homocysteine or one of its derivatives. Wilcken investigated this hypothesis and showed that patients with coronary artery disease (CAD) have abnormal homocysteine metabolism compared to control participants (3). Many effects of plasma homocysteine are due to its atherogenic and prothrombotic features (12).

When blood homocysteine level increases, a major part of homocysteine byproduct appears in the form of thiolactone that interacts with low-density lipoprotein (LDL) and creates LDL-homocysteine thiolactone. It is then collected by macrophages and becomes involved in foam cell formation, ultimately leading to formation of atherosclerotic plaques. Within these plaques, homocysteine thiolactone acylates proteins and alter vascular oxidative processes, resulting in arterial thrombosis. In addition, auto-oxidation of homocysteine leads to formation of superoxide and hydrogen peroxide. This oxygen-derived molecule can participate in LDL oxidation and cause endothelial dysfunction, and stimulate growth of vascular smooth muscle cells (13). Conversion of homocysteine to homocysteine thiolactone could be due to error in proofreading function of some aminoacyl tRNA synthetases. Homocysteine thiolactone is chemically active and easily acylates free amino acid groups of proteins (14). Free homocysteine thiolactone plasma levels range between zero to $35 \mathrm{nM}$ (mean of $2.82 \pm 6.13$ $\mathrm{nM}$ ), which accounts for almost $0.3 \%$ of the total homocysteine in plasma. The amount of homocysteine thiolactone is higher in urine (median of 145nM, 11-474 nM range, 2.5-28\% urinary homocysteine), while the renal clearance of homocysteine is $0.1-0.3 \%$ of creatinine renal clearance. In addition, clearance of homocysteine thiolactone is about $20-700 \%$ of creatinine clearance. This suggests that in some people, homocysteine thiolactone is not only filtered in glomeruli but also secreted into the peritubular space. Although there is no relationship between urinary homocysteine and homocysteine thiolactone, there is a positive association between homocysteine thiolactone concentrations in the urine and plasma. These data suggest that the urinary excretion is a main way of removing homocysteine thiolactone from the body. Homocysteine thiolactone attacks various proteins such as fibrinogen, albumin, transferrin, myoglobin, cytochrome $\mathrm{C}$ and alpha-2-macroglobulin in vitro and under physiological conditions $(\mathrm{pH}$ $7.4,37^{\circ} \mathrm{C}$ ). One of the side effects of protein homocysteinylation is blockage of lysine's $\varepsilon$ $\mathrm{NH} 2$ groups in collagen that impairs extracellular crosslinks of underlying fibers. Several mechanisms have been suggested that homocysteine thiolactone intensify atherogenesis. It is likely that homocysteinylated LDLs are more prone to oxidation. Since homocysteinylated LDLs bind to scavenger receptors instead of LDL receptors, they are collected more quickly by macrophages, leading to intracellular cholesterol accumulation and foam cell formation. Moreover, homocysteinylated LDLs induce oxidative stress, and are associated with endothelial dysfunction, a key event in the formation of atherosclerotic plaques. Oxidized LDL triggers an immune response (7).

The role of homocysteine in development of CVD

Temporary angina pectoris and acute 
myocardial infarction (MI) are clinically and pathologically similar. The term "acute coronary syndrome" is generally used for both diseases. From the pathological aspect, acute coronary syndrome is identified with detachment of an atherosclerotic plaque, platelet aggregation and active thrombotic process. Mild to moderate increase in circulating homocysteine is associated with increased prevalence of $\mathrm{CAD}$, peripheral vascular disease, stroke and venous thrombosis. Homocysteine can be toxic for the endothelium and reduce nitric oxide bioavailability. This leads to endothelial dysfunction and increased production of proinflammatory cytokines and smooth muscle cells, leading to atherosclerosis progression and plaque destabilization (15). One of the possible mechanisms for pathogenesis of homocysteine is that elevated homocysteine leads to endothelial dysfunction, reduction of nitric oxide release, increased LDL-oxidation, increased smooth muscle cell proliferation and platelet disorders. In normal populations, $10 \%$ of CAD cases are related to homocysteine, while hyperhomocysteinemia has been observed in $25 \%$ of patients with CAD. In adults, a $15 \mu \mathrm{mol} / \mathrm{L}$ increase in the total homocysteine level increases the risk of stroke and ischemic diseases by $50 \%$ and $30 \%$, respectively (1). Homocysteine increases collagen production and smooth muscle cells proliferation. Prothrombotic effects of homocysteine in patients with acute coronary syndrome and stroke include inhibition of protein $\mathrm{C}$ and heparin sulfate, increase in fibrinopeptide A and blood viscosity, activation of factors VIIa and V, and reduction of endothelial antithrombotic activity (6). The two mechanisms known to reduce hyperhomocysteinemia-induced fibrinolysis include changes in fibrinogen by homocysteinylation, development of fibrinogen-derived fibrin relatively resistant to plasmin and increase in thrombin-activatable fibrinolysis inhibitor activity. Other evidence supports the indirect role of angiostatic thrombin. TAFI-mediated increase in thrombin not only inhibits fibrinolysis but also prevents the formation of endothelial channels and angiogenesis. The inhibition of fibrinolysis decreases the release of fragments from proteolytic breakdown of fibrin that has angiogenic properties (16).

Mehta et al. on 21 patients with CAD and 20 healthy controls found no significant difference in the homocysteine level between the two groups $(12.9 \pm 2.3 \mu \mathrm{mol} / \mathrm{L}$ vs. $12.8 \pm 2.4$ $\mu \mathrm{mol} / \mathrm{L})(23)$. The contradiction between the mentioned study and other studies could be due to patient selection method or small sample size, so that the concentrations reported for the control group are similar to other studies, while the concentrations of homocysteine in patients were inconsistent with most other reports.

The effect of folic acid supplementation on reduction of homocysteine level has been investigated in several studies. In a double blind clinical trial by Wahab et al. on patients with AMI, $5 \mathrm{mg}$ folic acid or placebo were administered to the participants for four weeks. Folic acid supplementation significantly reduced homocysteine level, but no significant change was observed in the placebo group (24). In another study on 5522 patients aged $>55$ years with vascular disease or diabetes, a combination of folic acid, vitamin $\mathrm{B} 6$, vitamin $\mathrm{B} 12$, or placebo was administered to the participants for an average of five years. Mean plasma homocysteine level reduced by $2.4 \mu \mathrm{mol} / \mathrm{L}$ and increased by 0.8 $\mu \mathrm{mol} / \mathrm{L}$ in the treated and placebo groups, respectively. Primary outcomes (MI, stroke, cardiovascular causes) were not significantly different between 519 patients under treatment (18.8\%) and 547 patients who took placebo (19.8\%) (Relative risk 0.95, 95\% CI, 0.84 vs. $1.07, \mathrm{P}=0.41$ ) (25). Based on the results of this study, it can be concluded that the consumption of supplements after development of the disease has no prominent role in the recurrence and progression of the disease. Similar results have been reported by other studies $(26,27)$. Although the consumption of supplements causes a slight 
reduction in homocysteine level, it does not have a significant effect on mortality rates associated with complications of these diseases.

The association of homocysteine with serum antioxidant level in the patients with CVD and other diseases has been also investigated. A study reported increased levels of serum homocysteine, superoxide dismutase and red blood cell (RBC) count in patients with MI compared to controls. However, the increase in superoxide dismutase level was not statistically significant (28). Another study investigated the relationship of serum glutathione peroxidase (GPx) and RBC with serum homocysteine level in patients with MI. GPx activity in RBC of patients and controls had no statistically significant difference, but serum activity of this enzyme differed significantly between the two groups. It seems that the increase in GPx is due to cell damage, which is followed by inhibition of free radicals and damages to the cells (29).

\section{Genetic studies}

In study of Sultan et al. on 20 patients with $\mathrm{CAD}, 20$ stroke patients and 20 healthy controls, homocysteine level was significantly higher in the patients with CAD $(16.12 \pm 5.09$ $\mu \mathrm{mol} / \mathrm{L})$ and stroke patients $(16.79 \pm 5.93$ $\mu \mathrm{mol} / \mathrm{L})$ compared to controls $(10.43 \pm 2.57$ $\mu \mathrm{mol} / \mathrm{L})$. A study on the MTHFR C677T mutation showed that homocysteine level is significantly higher in TT (18.26 2.75 $\mu \mathrm{mol} / \mathrm{L})$ and $\mathrm{CT}(17.60 \pm 7.22 \mu \mathrm{mol} / \mathrm{L})$ compared to CC $(12.94 \pm 4.16 \mu \mathrm{mol} / \mathrm{L})$. In genotype $A 1298 C$, there was no significant difference in the mean homocysteine level between genotypes AA $(14.14 \pm 4.32 \mu \mathrm{mol} / \mathrm{L})$, AC $(14.25 \pm 5.50 \mu \mathrm{mol} / \mathrm{L})$ and $\mathrm{CC}(16.28 \pm 8.76$ $\mu \mathrm{mol} / \mathrm{L}$ ) (30). Similar results were observed in the study of Bennouar et al. on 210 patients with CAD and 190 healthy controls. The frequency of $C 677 T$ genotypes was $11.8 \%$ for TT, $53 \%$ for CC and $34.8 \%$ for CT. The frequency of genotypes differed significantly between the two groups. Patients with CAD had significantly higher homocysteine level than the control group (31). However, study of
Lin et al. on 121 patients with at least $50 \%$ stenosis in one of the main coronary arteries and 155 healthy control participants reported no significant difference in homocysteine level (Patients $10.7 \pm 5.60 \mu \mathrm{mol} / \mathrm{L}$ vs. controls $9.60 \pm 2.20 \mu \mathrm{mol} / \mathrm{L})$. The mentioned study stated that the plasma homocysteine level is associated with an increased risk of CAD, independent from the MTHFR $677 \mathrm{C} \rightarrow \mathrm{T}$ mutation (32). Study of Freitas et al. on 298 patients with CAD and 510 controls reported that hyperhomocysteinemia is significantly higher in patients with 677TT and 1298AA genotypes. No significant difference was observed in MTHFR677 genotype distribution between the two groups, but there was a significant increase in the frequency of 1295AA genotype in patients with CAD (33). Several studies have been conducted on the prevalence of various MTHFR genotypes and their association with homocysteine level (3436). Inconsistency in the results of such studies indicates the impact of race and ethnicity on the prevalence of different genotypes and their association with plasma homocysteine levels.

\section{Homocysteine and diabetes}

Laghari et al. divided 107 patients with MI into a diabetic and a non-diabetic group, and found that homocysteine level was significantly higher in diabetics compared to non-diabetics $(23.14 \pm 2.4 \mu \mathrm{mol} / \mathrm{L}$ vs. $13.1 \pm 1.8$ $\mu \mathrm{mol} / \mathrm{L}$ ) (37). Study of Akalin et al. on 90 patients with type 2 diabetes (41 patients with atherosclerosis and 49 patients without vascular complications) reported that the homocysteine level was significantly higher in patients with atherosclerosis (13.840 \pm 0.95 $\mu \mathrm{mol} / \mathrm{L})$ than in those without atherosclerosis $(10.725 \pm 0.59 \mu \mathrm{mol} / \mathrm{L})(38)$. In the study of Ramachandran et al. (2012) on 50 diabetic patients and 30 healthy controls, diabetic patients were divided into two groups of with complications $(\mathrm{n}=19)$ and without diabetic complications $(\mathrm{n}=31)$. Levels of homocysteine and other conventional variables such as hemoglobin A1C, lipid profile and 
microalbuminuria were measured to determine the complications of type 2 diabetes. Homocysteine level was significantly higher in patients with diabetic complications (3.0095 $\mu \mathrm{g} / \mathrm{ml}$ vs. $2.3037 \mu \mathrm{g} / \mathrm{ml})$. It was also significantly higher in diabetic patients with CAD $\quad(\mathrm{P}=0.002)$, stroke $(\mathrm{P}=0.000)$ and neuropathy $(\mathrm{P}=0.000)$ in comparison with the control group. Triglycerides and hemoglobin A1C had a positive correlation with homocysteine level (39). In recent years, many reports have been published on the association of homocysteine with exacerbation of diabetic complications (40-42). The results of these studies indicate that vitamin B12, folic acid and homocysteine should be evaluated in diabetic patients and if necessary, medical intervention should be taken into account to keep homocysteine level low.

\section{Homocysteine and thyroid disorders}

Study of Cakal et al. on 20 patients with overt hypothyroidism and 15 patients who had been recently diagnosed with hypothyroidism have shown that pre-treatment homocysteine level was similar to patients with subclinical hypothyroidism and controls. However, the pre-treatment homocysteine level was significantly higher in patients with overt hypothyroidism than in control subjects $(10.3 \pm 3.4 \mu \mathrm{mol} / \mathrm{L}$ vs. $7.9 \pm 0.6 \mu \mathrm{mol} / \mathrm{L})$. In addition, post-treatment homocysteine level decreased significantly in patients with overt hypothyroidism (43). Study of Rahbani et al. on 60 patients with thyroid disorders (30 patients with hyperthyroidism and 30 with hypothyroidism) and 30 healthy controls reported the mean homocysteine level as $7.79 \pm 1.44 \mu \mathrm{mol} / \mathrm{L}$ for hyperthyroid patients, $17.09 \pm 6.93 \mu \mathrm{mol} / \mathrm{L}$ for hypothyroid patients, and $8.08 \pm 1.92 \mu \mathrm{mol} / \mathrm{L}$ for controls. A significant increase was observed in hypothyroid patients compared to controls (44). In study of Purice et al., mean homocysteine level was determined as $14.40 \pm 5.6,16.56 \pm 5.3$ and $9.24 \pm 1.19 \mu \mathrm{mol} / \mathrm{L}$ for the patients with moderate hypothyroidism, severe hypothyroidism and healthy controls, respectively. Both groups of patients had significantly higher homocysteine level than the control group. Three months of treatment with levothyroxine and folic acid significantly reduced the homocysteine level in the patients with moderate hypothyroidism. Their homocysteine level returned to normal level after six months, while patients with severe hypothyroidism had normal homocysteine level after three months (45). Study of Sutken et al. reported the homocysteine level of 23 hyperthyroid patients as $10.4 \pm 0.3$ and $14.50 \pm 0.3 \mu \mathrm{mol} / \mathrm{L}$ before and after treatment, respectively. The researchers found that homocysteine level was significantly increased after treatment. They concluded that vitamin B12 and folic acid supplementation is essential for prevention of increased homocysteine level in the patients with hyperthyroidism (46). In the study of Gunduz et al., homocysteine level was $12.76 \pm 3.11 \mu \mathrm{mol} / \mathrm{L}$ in the patients with subclinical hypothyroidism, $15.05 \pm 9.87$ $\mu \mathrm{mol} / \mathrm{L}$ in clinical hypothyroid patients, $11.93 \pm 3.72 \mu \mathrm{mol} / \mathrm{L}$ in the patients with subclinical hyperthyroidism and 10.23 \pm 3.13 $\mu \mathrm{mol} / \mathrm{L}$ in patients with clinical hyperthyroidism. Homocysteine level was higher in hypothyroid patients compared to that of control group $(\mathrm{P}=0.003)$, but no difference was observed between hypothyroid and hyperthyroid patients (47). According to several reports published on the frequency of thyroid disorders such as study of Neves et al. (48), it can be concluded that homocysteine level increases in thyroid disorders. It is noteworthy to mention that this increase can be seen in the cases of hypothyroidism and hyperthyroidism, which makes difficult the interpretation of the mechanism of impact of thyroid disorders on homocysteine level or the effect of increased homocysteine level on thyroid function. However, all studies demonstrated the positive impact of taking supplements with thyroid medications on reducing homocysteine level and prevention of vascular complications.

\section{Homocy0.steine and multiple sclerosis (MS)}

Ex vivo studies have shown that homocysteine, even at physiological 
concentration $(10 \mu \mathrm{mol} / \mathrm{L})$, have multiple toxic effects on neurons including oxidative stress, mitochondrial dysfunction, accumulation of cytosolic calcium, activation of apoptotic pathway and induction of neuronal inflammation. It is known that all these mechanisms are involved in the pathogenesis and progression of several diseases such as MS (49). Homocysteine plays a role in oxidative stress, biochemical stimulation of $\mathrm{N}$ methyl-D-aspartate receptors, DNA damage and mitochondrial dysfunction. Homocysteine level is significantly increased in the patients with MS and have an inverse relationship with vitamin B12 level. Moreover, small amounts of vitamin B12 in the cerebrospinal fluid and normal serum levels of this vitamin in patients with MS have been observed. Vitamin B12 deficiency can lead to functional impairments in these patients even before the manifestation of clinical symptoms. In the study of Kocer et al. on 35 patients with MS during an acute attack and 30 healthy controls, MS patients had lower serum level of vitamin B12 (20\%) and folate (14.3\%) than the controls. However, low level of vitamin B12 and folate were observed only in $3.3 \%$ of the control participants. Level of homocysteine was high in $20 \%$ of the patients with MS, while it was in the normal range in control group. No significant difference was found in the variables between patients and controls (50). Meanwhile, Sabry et al. reported that homocysteine level is significantly higher in the patients with MS than that of controls, and vitamin B12 and folate in these patients were slightly lower than those in the control ones (51). Similar results have been reported by studies of Salemi et al. (52) and Triantafyllou et al. (53). In the study of Zoccolella et al. on 217 MS patients and 219 with neurologic disease (as controls), the mean homocysteine level in MS patients was slightly higher than that of controls. The mean homocysteine level was higher in males compared to females. However, no significant difference was found in homocysteine concentration between males and females of the control group.
Homocysteine level in males was higher than that in males (49). Although one cannot be definite about the role of homocysteine in the development of MS, structural changes in the proteins are expected due to the effect of this amino acid, and its increased level can lead to exacerbation of the disease. Due to the neurodegenerative effects on the blood-brain barrier, hyperhomocysteinemia can be studied as a risk factor for diseases such as MS.

\section{Homocysteine and depression}

Folate and vitamin B12 are essential for normal functioning of the central nervous system and severe deficiency of these vitamins could lead to memory loss, intellectual disability and depression. Active metabolite of folate is necessary for remethylation of homocysteine and methionine production, which is useful in various biochemical processes (54). Hyperhomocysteinemia is associated with dementia in old age due to neurotoxic effects, and its role in causing depression has been recently proposed. Insufficient amounts of folate and vitamin B12 are also involved in the impairment of synthesis of neurotransmitters and other molecules involved in regulation of the mental state. Most evidence supports the link between high homocysteine level, low folate and vitamin B12 level and depression. Forti et al. followed up 240 men and 217 women for four years to assess depression. Only in women, homocysteine level was associated with the prevalence of depression. Moreover, the women with low folate and vitamin B12 levels had the highest level of homocysteine (55). In a study by Almeida et al. on 3752 men aged $\geq 70$ years, odds ratio (OR) for prevalence of depression (1.04 OR, 95\% CI, 1.02-1.05) increased by $40 \%$ with one unit increase in the homocysteine level. The results showed that the older people with high homocysteine level have an increased risk of developing depression (1.07 OR, 95\% CI, 1.38-2.08) (56). Study of Pascoe et al. (2012) conducted on 149 post-stroke elderly patients found that homocysteine level was significantly associated with the symptoms of depression in 
these patients. The patients with abnormal homocysteine level had twice more depression symptoms than those with normal homocysteine level (57).

In the study of Watanabe et al. on 85 pregnant women in their first trimester of pregnancy, 53 women (61.6\%) had depression. Logistic regression analysis showed no significant correlation between increased level of homocysteine, folate and vitamin B12 deficiency and the frequency of depression. The mean homocysteine level was 6.0 $\mathrm{nmol} / \mathrm{mL}$ in depressed women and 6.1 $\mathrm{nmol} / \mathrm{mL}$ in non-depressed women. Folate level was $8.0 \mathrm{ng} / \mathrm{mL}$ in depressed women and $8.2 \mathrm{ng} / \mathrm{mL}$ in the non-depressed women (54).

The results of these studies indicate that not all types of depression can be attributed to increased homocysteine level. The majority of studies that have suggested a positive correlation between increased homocysteine and depression were related to old people. In other words, continuous changes are required for the effects of this amino acid on the process of depression that occur in old age. There are some contradictory results that may require a new mechanism for tracking the functioning pathway of this mysterious amino acid. For example, Alexopoulos et al. studied the cognitive function of 25 healthy individuals and 40 depressed elderly. The depressed patients with higher homocysteine level had better cognitive function than the patients with homocysteine levels $\leq 11.7$ $\mu \mathrm{mol} / \mathrm{L}$. the homocysteine level had a positive correlation with phonological processes $(\mathrm{P}=0.002)$. The mean homocysteine level was $11.32 \pm 4.87 \mu \mathrm{mol} / \mathrm{L}$ and $14.02 \pm 6.47 \mu \mathrm{mol} / \mathrm{L}$ in the controls and depressed patients, respectively. These researchers claimed that there is a positive correlation between homocysteine level, verbal expression and psychomotor speed under certain circumstances in depression in old age (58).

\section{Homocysteine and Alzheimer's disease (AD)} In the study of $\mathrm{Tu}$ et al., 92 patients with $\mathrm{AD}$ were followed up for 2 years and compared with 67 healthy old individuals. Homocysteine level showed no correlation with neuropsychological tests (monitoring cognitive function and mini-mental status examination) but had a positive correlation with reduced overall rating for monitoring cognitive function ( $\mathrm{r}=-0.357$ and $\mathrm{P}=0.006)$ and abstract thinking $(r=-0.347$ and $P=0.01)$. No significant difference was found between the mean serum homocysteine levels of the study groups (59). In the study of Saczynski et al. in 2010, among 949 patients that were followed up for 17 years, 824 had no symptoms of depression at baseline and 125 had depression symptoms. The mean homocysteine level at baseline was 12.1 in patients with depression symptoms and 11.0 in those without symptoms of depression $(\mathrm{P}=0.064)$. After 17 years, 136 were diagnosed with $\mathrm{AD}$. The homocysteine level in the depressed patients who were diagnosed with dementia were 1.5 times more than those who were not depressed (1.72 HR, 95\% CI, 1.042.84, $\mathrm{P}=0.035$ ) (60). Li et al. (2008) studied 191 patients with $\mathrm{AD}$ and reported that the mini-mental state examination was inversely associated with homocysteine levels ( $\mathrm{r}=-0.169$ and $\mathrm{P}=0.024)$, while homocysteine increased significantly with age $(\mathrm{r}=0.312$ and $\mathrm{P}<0.001)$ (61). In the study of Weiner et al. on 11 American-Indian patients with $\mathrm{AD}$ and 10 Indian control participants, mean plasma homocysteine level was higher in AD patients (11 vs. $9.8 \mu \mathrm{mol} / \mathrm{L}$ ), but the difference was not significant (62). In 2011, Rajagopalan et al. studied 732 old people consisting of 203 healthy indivituals, 173 with $\mathrm{AD}$ and 356 with mild cognitive impairment. The participants with higher homocysteine level had more white matter atrophy in the brain tissue. This association was found even when the people with mild cognitive impairment were considered separately. Vitamin B supplements such as folate can prevent the homocysteineassociated atrophy. On average, those with hyperhomocysteinemia had less score in the short-term memory test compared to those without hyperhomocyteinemia. Homocysteine level in the people with $\mathrm{AD}(\mathrm{P}=0.0018)$ and 
mild cognitive impairment $(\mathrm{P}=0.015)$ was higher than that in controls (63). With aging, the absorption of vitamins becomes impaired, especially vitamin B12. The reduced vitamin level is accompanied with an increased level of homocysteine in blood, which could be one of the mechanisms that cause dementia in old age. However, one cannot come to a definitive judgment only because the increased homocysteine level is accompanied with aging. If studies report that the reduced homocysteine level, which is caused by vitamins supplementation, could stop the disease progression, this cause and effect relationship could be further studied. But until then, it is recommended to measure vitamin B12, folic acid and homocysteine in elderly.

\section{Homocysteine and preeclampsia}

Fei et al. conducted a study on pregnant women consisting of 30 healthy participants, 15 with pregnancy-induced hypertension (PIH) and 40 with preeclampsia. Compared to healthy pregnant women, homocysteine level was significantly higher in the pregnant women with preeclampsia and PIH. The mean homocysteine level in the women with severe preeclampsia $(\mathrm{n}=22)$ and with mild preeclampsia $(\mathrm{n}=18)$ was $26.4 \pm 2.33 \mu \mathrm{mol} / \mathrm{L}$ and $19.1 \pm 3.98 \mu \mathrm{mol} / \mathrm{L}$, respectively. The mean homocysteine level was $10.3 \pm 2.06$ $\mu \mathrm{mol} / \mathrm{L}$ in healthy pregnant women and $15.9 \pm$ $2.46 \mu \mathrm{mol} / \mathrm{L}$ in ones with hypertension (64). In the study of Javadi et al. on 60 pregnant women without hypertension, 55 with mild preeclampsia and 53 with severe preeclampsia, the homocysteine level in the women with severe preeclampsia was significantly higher than that of controls. However, no significant difference was found between the control group and the patients with mild preeclampsia (65). In the study of Mahdavian et al. (2011) on 30 pregnant women with preeclampsia and 30 women with normal blood pressure, the two groups had no difference in terms of amount and duration of folic acid supplementation during pregnancy but had significant differences in term of homocysteine level. No and duration of folic acid consumption. The mean homocysteine level was $9.16 \pm 4.54$ and $8.22 \pm 3.38 \mu \mathrm{mol} / \mathrm{L}$ in the preeclampsia and control groups, respectively $(\mathrm{P}=0.01)$ (66). Laskowska et al. examined 49 pregnant women with normal blood pressure and intrauterine growth restriction (IUGR), 31 with preeclampsia and IUGR, 35 with preeclampsia and newborns with suitable birth weight and 47 healthy pregnant women with normal blood pressure as controls. A high level of homocysteine was observed in the women with IUGR compared to controls. The Homocysteine level was higher in the women with preeclampsia. The highest level of homocysteine was observed in the women with preeclampsia and newborns with suitable birth weight (67). In a study by Khosrowbeygi et al., 30 pregnant women with preeclampsia and 30 healthy pregnant women were studied. The homocysteine level was significantly higher in the women with preeclampsia compared to controls. In addition, the homocysteine level was significantly higher in the women with severe preeclampsia than that in the women with mild preeclampsia. The homocysteine level was $5.72 \pm 0.18$ and $17.18 \pm 1.12 \mu \mathrm{mol} / \mathrm{L}$ in healthy pregnant women and women with preeclampsia, respectively (68). Similar results have been reported by Rahimi et al. (69) and Mao et al. (70). In a study conducted in 2011 by Mujawar et al., 50 pregnant women with preeclampsia and 50 normal controls were followed up for three years. In the preeclampsia group, homocysteine, folic acid and vitamin B12 levels had significant changes in comparison with those in the control group. Moreover, an inverse relationship was observed between homocysteine, folic acid and vitamin B12 in the patients with preeclampsia (71). The published reports on the relationship between homocysteine level and preeclampsia not only confirm this relationship, but also show an association between plasma homocysteine level and severity of preeclampsia. Increasing relationship was found between homocysteine 
gestational age is accompanied with an increased need of body for vitamins, especially folic acid and vitamin B12. The reduced level of these vitamins is accompanied with an increased plasma homocysteine level. Due to multiple mechanisms, homocysteine can increase blood pressure and exacerbate the symptoms and complications of preeclampsia by affecting blood vessels.

\section{Homocysteine and Parkinson's disease}

Study of El-Motayam et al. performed the mini mental status examination test on 42 patients under treatment with LDopa/carbidopa and 18 healthy controls, and classified the patients into two groups of patients with cognitive impairment $(n=12)$ and without cognitive impairment $(n=30)$. The patients of group I had significantly higher homocysteine level and cognitive and motor impairment compared to that of group II. There was a significant positive correlation between homocysteine level and the severity of the disease (72). In the study of Lee et al., 28 patients under treatment with LDopa/carbidopa, 25 with L-Dopa/carbidopa inhibitors and 23 controls were followed up for more than a year. The homocysteine level in the patients treated with L-Dopa/carbidopa $(14.9 \pm 5.3 \mu \mathrm{mol} / \mathrm{L})$ increased significantly compared to the group treated with inhibitors of L-Dopa/carbidopa $(11.9 \pm 5.3 \mu \mathrm{mol} / \mathrm{L})$ and the control group $(11.1 \pm 2.5 \mu \mathrm{mol} / \mathrm{L})$. In addition, homocysteine had an inverse relationship with the number of endothelial progenitor cells (73). Zhang et al. studied 88 patients with Parkinson's disease and vascular Parkinsonism (VP). Homocysteine levels were $14.50 \pm 5.82 \mu \mathrm{mol} / \mathrm{L}$ in the patients with Parkinson's disease aged $\leq 60$ years and 13.65 $\pm 3.18 \mu \mathrm{mol} / \mathrm{L}$ in patients aged $>60$ years. Homocysteine level in the patients with VP aged $\leq 67$ years $(12.78 \pm 3.88 \mu \mathrm{mol} / \mathrm{L})$ differed significantly with that of in patients aged $>67$ $(16.79 \pm 5.55 \mu \mathrm{mol} / \mathrm{L})(74)$. In an interventional study by Nevrly et al., the homocysteine level of two groups including a group of 30 patients under long-term L-Dopa treatment and a second group of 10 patients treated with L-
Dopa+entacapone were compared. The mean level of homocysteine was higher in the first group than that of the second group. No significant difference was observed in the homocysteine level of the two groups after the addition of entacapone to L-Dopa. These results suggest that those under long-term treatment with L-Dopa have increased plasma level of homocysteine (75). The Study of Muller et al. on 28 patients with Parkinson's disease under treatment with LDopa/carbidopa showed that the treatment with L-Dopa/carbidopa increased homocysteine to the level higher than the 15 $\mu \mathrm{mol} / \mathrm{L}$ threshold (76). In Isobe et al. study on 18 patients with Parkinson's disease before and after treatment with L-Dopa and 16 healthy individuals, the homocysteine level increased significantly after the treatment $(169 \pm 27 \mathrm{nM})$ compared to pre-treatment $(111 \pm 22 \mathrm{nM}$, $\mathrm{P}<0.0001)$ and control participants $(85 \pm 25$ $\mathrm{nM}, \mathrm{P}<0.005)(77)$. The Studies on the patients with Parkinson's disease have indicated that the homocysteine level in these patients is higher than that of healthy individuals. However, Isoble's comparison of results before and after treatment with L-Dopa indicated that the consumption of the drug itself resulted in a further increase in homocysteine level. Therefore, continuous monitoring of plasma homocysteine level in these patients is recommended to prevent exacerbation and complications of the disease.

\section{Homocysteine and other diseases}

Other causes of hyperhomocysteinemia include kidney disorders, antiepileptic drugs, methotrexate and a high-protein diet (78). The increased age and male gender are associated with the level of hyperhomocysteinemia. Increased homocysteine level has been observed in postmenopausal women. Some diseases such as acute renal dysfunction, hypothyroidism and inflammatory bowel disease are associated with hyperhomocysteinemia (79). The elevated level of total homocysteine is a strong predictor of restenosis and complications of coronary angioplasty (80). 
Figure 1 -Pathway of homocysteine metabolism

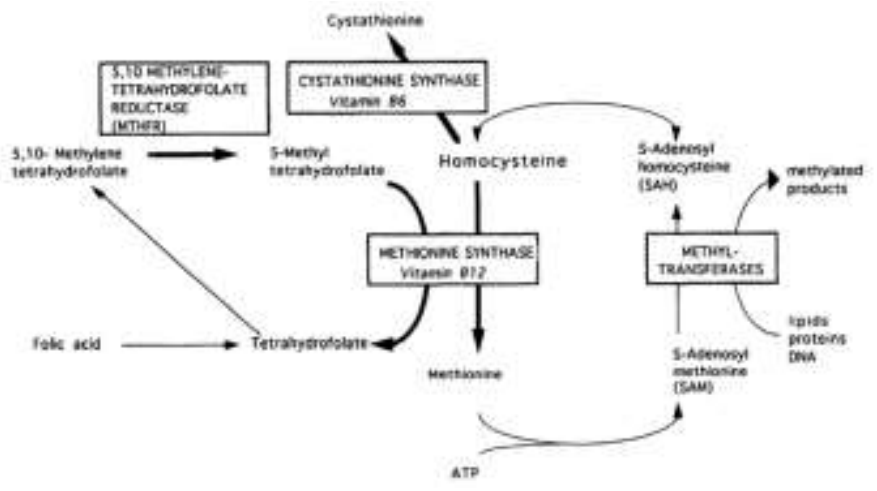

\section{CONCLUSION}

Homocysteine level increases with age. Moreover, the absorption of micronutrients, especially vitamin B12, decreases in old age that could cause a further increase in homocysteine level. On the other hand, elasticity of blood vessels decline with aging, and increased levels of homocysteine accelerate atherosclerosis. The sum of these processes highlights the role of homocysteine in the development and exacerbation of several diseases. Therefore, it is recommended to consider seriously measurement of this amino acid and vitamins related to its

\section{REFERENCES}

1. Khosravi A, Peyman P, Sayemiri K, Saki K, Ranjbar R. Evaluation of Sera Hemocystein and Lipoprotein (a) levels in relation to other risk factors of cardiovascular diseases. Health System Research. 2010; 6(2): 326-334.

2. Kazemi T, Sharif Zadeh GhR. Ten-year changes in mortality and risk factors in acute myocardial infarction in Birjand, 1994-2003. Ofogh-e-Danesh. 2004; 10(3): 38-42.

3. Ghatreh Samani K, Roghani F, Farrokhi E. Evaluation of correaltion between plasma homocysteine and oxidized low-density lipoprotein in patients with coronary artery disease. Journal of Birjand University of Medical Sciences. 2009; 16 (3): 47-53.

4. Frick B, Rudzite V, Schrocksnadel K, Kalnins U, Erglis A, Trusinskis $\mathrm{K}$, et al. Homocysteine, B vitamins and immune activation in coronary heart disease. Pteridines-Berlin-. 2003; 14(3): 82-7.

5. Voutilainen S, Lakka T, Hämelahti P, Lehtimäki T, Poulsen H, Salonen J. Plasma total homocysteine concentration and the risk of acute coronary events: the Kuopio Ischaemic Heart Disease Risk Factor Studytpdel. Journal of internal medicine. 2000; 248(3): 217-22. metabolism in the people at risk, especially in old age.

\section{ACKNOWLEDGEMENT}

We hereby acknowledge and express our gratitude to our colleagues in the Departments of Laboratory Sciences and Biochemistry of the Golestan University of Medical Sciences for their valuable advices.

\section{CONFLICT OF INTEREST}

The authors declare that they have no conflict of interests.

6. Chauhan AP, Tailor PB, Joshi R, Bhabhor P. Evaluation of Serum Homocysteine as an Independent Risk Factor for Myocardial Infarction in Young Patients. National Journal of Medical Research. 2012; 2(4): 423-6.

7. Bełtowski J. Protein homocysteinylation: a new mechanism of atherogenesis? Modyfikacja białek przez tiolakton homocysteiny-nowy mechanizm powstawania miażdżycy? Journal cover. 2013; 67.

8. Voutilainen S, Virtanen JK, Rissanen TH, Alfthan G, Laukkanen J, Nyyssönen K, et al. Serum folate and homocysteine and the incidence of acute coronary events: the Kuopio Ischaemic Heart Disease Risk Factor Study. The American journal of clinical nutrition. 2004; 80(2): 317-23.

9. Qujeq D, Hossini L, Salehi Omran MT. Relationship of Total Homocysteine, Cholesterol, Triglyceride in the Serum and Diastolic Blood Pressure of Patients with Myocardial Infarction. Iranian Biomedical Journal. 2001; 5(2): 97-101.

10. Harmon D, Woodside J, Yarnell J, McMaster D, Young I, McCrum E, et al. The common 'thermolabile'variant of methylene tetrahydrofolate reductase is a major determinant of mild hyperhomocysteinaemia. Qjm. 1996; 89(8): 571-7. 
11. Kluijtmans LA, Young IS, Boreham CA, Murray L, McMaster D, McNulty H, et al. Genetic and nutritional factors contributing to hyperhomocysteinemia in young adults. Blood. 2003; 101(7): 2483-8.

12. Al-Obaidi MK, Stubbs PJ, Collinson P, Conroy R, Graham I, Noble MI. Elevated homocysteine levels are associated with increased ischemic myocardial injury in acute coronary syndromes. Journal of the American College of Cardiology. 2000; 36(4): 1217-22.

13. Abraham R, John MJ, Calton R, Dhanoa J. Raised serum homocysteine levels in patients of coronary artery disease and the effect of vitamin B12 and folate on its concentration. Indian Journal of Clinical Biochemistry. 2006; 21(1): 95-100.

14. Jakubowski H. Protein homocysteinylation: possible mechanism underlying pathological consequences of elevated homocysteine levels. The FASEB Journal. 1999; 13(15): 2277-83.

15. Omland T, Samuelsson A, Hartford M, Herlitz J, Karlsson T, Christensen B, et al. Serum homocysteine concentration as an indicator of survival in patients with acute coronary syndromes. Archives of internal medicine. 2000; 160(12): 1834-40.

16. Loscalzo J. Homocysteine-mediated thrombosis and angiostasis in vascular pathobiology. The Journal of clinical investigation. 2009; 119(11): 3203.

17. Nusier MK, El-Dwairi QA. Effects of vitamin B12 and folic acid on hyperhomocysteinemia in patients with acute myocardial infarction. Journal of health science. 2007; 53(1): 16-22.

18. Valiūnienė J, Jablonskienè V, Kučinskienè ZA. Homocysteine and lipid peroxidation markers in patients with coronary heart disease. Biologija. 2007; 53(4): 2933.

19. Valjevac A, Dzubur A, Icindic E, Dzuvo A, Zaciragic $\mathrm{A}$, Lepara $\mathrm{O}$, et al. Change in serum homocysteine level follow two different trends in patients during early post myocardial infarction period. Bosnian Journal Of Basic Medical Sciences. 2009; 9(2): 161-165.

20. Joshaghani HR, Shirafkan A, Marjani A. Serum homocysteine levels in patients with myocardial infarction in Gorgan( In Northern Iran). Asian journal of Biochemistry. 2007; 2(2): 157-160.

21. Ghaedi M, Haji Zeinali AM, Boroumand MA, Abbasi SH. Homocysteine level in CAD patients of Iranian population. Iranian Cardiovascular Research Journal. 2007; 1(2): 92-7.

22. Vishnu Priya V, Surapaneni K M. Erythrocyte Lipid Peroxidation, Glutathione, Ascorbic Acid,Vitamin E, Antioxidant Enzymes And Serum Homocysteine Levels In Patients With Coronary Artery Disease. Journal of Clinical and Diagnostic Research. 2008; 2(8): 11801185.

23. Mehta Sr M, Shah J. Absence of Association Between Serum Homocysteine Levels and Coronary Artery Disease. Indian Medical Gazette. 2012; 145(7): 253-256.

24. Wahab M, Zafreen F, Siddique M, Akter Y, Parveen $\mathrm{Z}$, Chowdhury $\mathrm{N}$, et al. Effect of folic acid supplementation on serum homocysteine and lipid profile in acute myocardial infarction. JAFMC 2009; 5(2): 2123.
25. Lonn E, Yusuf S, Arnold M, Sheridan P, Pogue J, Micks M, et al. Homocysteine lowering with folic acid and $B$ vitamins in vascular disease. The New England journal of medicine. 2006; 354(15):1567-77. DOI: 10.1056/NEJMoa060900.

26. Bønaa KH, Njølstad I, Ueland PM, Schirmer H, Tverdal A, Steigen T, et al. Homocysteine lowering and cardiovascular events after acute myocardial infarction. New England Journal of Medicine. 2006; 354(15): 157888.

27. Armitage JM, Bowman L, Clarke RJ, Wallendszus $\mathrm{K}$, Bulbulia R, Rahimi K, et al. Effects of homocysteinelowering with folic acid plus vitamin B12 vs placebo on mortality and major morbidity in myocardial infarction survivors. JAMA: The Journal of the American Medical Association. 2010; 303(24): 2486-94.

28. Joshaghani HR, Shafiee A. Correlation between serum and erythrocyte superoxide dismutase with serum homocysteine in myocardial infarction. Ofogh-e-danesh, Journal of Gonabad University of Medical Sciences And Health Services. 2007; 13(1): 5-9.

29. Joshaghani H, Bandegi A. Comparison of serum and erythrocyte superoxide dismutase in myocardial infarction and healthy people. koomesh. 2007; 8(3): 117122.

30. Sultan IE, Abbas H, El-Reweny AA, Khalafala OA, El-Abd D, Mosaad N. Effect of Methylenetetrahydrofolate Reductase Gene Mutation on Plasma Homocysteine Level and its Prevalence in Arterial Diseases. Journal of Taibah University Medical Sciences. 2006; 1(1): 20-29.

31. Bennouar N, Allami A, Azeddoug H, Bendris A, Laraqui A, El Jaffali A, et al. Thermolabile methylenetetrahydrofolate reductase C677T polymorphism and homocysteine are risk factors for coronary artery disease in moroccan population. $\mathrm{J}$ Biomed Biotechnol. 2007; 2007(1): 80687.

32. Lin P-T, Huang M-C, Lee B-J, Cheng C-H, Tsai T-P, Huang Y-C. High plasma homocysteine is associated with the risk of coronary artery disease independent of methylenetetrahydrofolate reductase $677 C-->T$ genotypes. Asia Pacific journal of clinical nutrition. 2008; 17(2): 330-8.

33. Freitas AI, Mendonça I, Guerra G, Brión M, Reis RP, Carracedo A, et al. Methylenetetrahydrofolate reductase gene, homocysteine and coronary artery disease: the A1298C polymorphism does matter. Inferences from a case study (Madeira, Portugal). Thrombosis research. 2008; 122(5): 648-56.

34. Tripathi R, Tewari S, Singh PK, Agarwal S. Association of homocysteine and methylene tetrahydrofolate reductase (MTHFR C677T) gene polymorphism with coronary artery disease $(C A D)$ in the population of North India. Genet Mol Biol. 2010; 33(2): 224-8. doi: 10.1590/S1415-47572010005000026.

35. Gupta SK, Kotwal J, Kotwal A, Dhall A, Garg S. Role of homocysteine \& MTHFR C677T gene polymorphism as risk factors for coronary artery disease in young Indians. The Indian journal of medical research. 2012; 135(4): 506-12. 
36. Eftychiou C, Antoniades L, Makri L, Koumas L, Costeas PA, Kyriakou E, et al. Homocysteine Levels and MTHFR Polymorphisms in Young Patients with Acute Myocardial Infarction: A Case Control Study. Hellenic J Cardiol. 2012; 53(3):189-94.

37. Laghari A, Memon A, Mushtaque Shah A, Ahmed S, Memon M. Hyperhomocysteinemia, a Risk Factor for Myocardial Infarction in Patients with Type-2 Diabetes in Southern Sindh, Pakistan. Pakistan Journal of Nutrition. 2009; 8(11): 1753-1755.

38. Akalin A, Alatas O, Colak O. Relation of plasma homocysteine levels to atherosclerotic vascular disease and inflammation markers in type 2 diabetic patients. European Journal of Endocrinology. 2008; 158(1): 4752.

39. Ramachandran L, Negi N, Gupta B. Prevalence of hyperhomocysteinaemia in type-2 diabetes mellitus and its correlation with its complications. Journal, Indian Academy of Clinical Medicine. 2012; 13(4): 277-81.

40. Balu Mahendran K, Santha K, Santhosh Kumar N, Gnana Desigan N, Mohammad A. Serum homocysteine and lipid profile levels in type 2 diabetes mellitus patients. International Journal of Medical Research \& Health Sciences. 2013; 2(2): 200-205.

41. Howlader H, Ahmed S, Sultana N, Hasan Z, Sadia U, Ferdousi S. Serum Homocysteine Level in Type 2 Diabetes Mellitus with Peripheral Arterial Disease. Bangladesh J Med Biochem. 2013; 6(1): 14-18.

42. Kibirige D, Mwebaze R. Vitamin B12 deficiency among patients with diabetes mellitus: is routine screening and supplementation justified?Journal of Diabetes \& Metabolic Disorders. 2013, 12:17. DOI: 10.1186/2251-6581-12-17.

43. Çakal B, Çakal E, Demirbaş B, Özkaya M, Karaahmetoğlu S, Serter R, et al. Homocysteine and fibrinogen changes with L-thyroxine in subclinical hypothyroid patients. Journal of Korean medical science. 2007; 22(3): 431-5.

44. Rahbani-Nobar M, Bahrami A, Norazarian M, Dolatkhah H. Correlation between serum levels of cholesterol and homocysteine with oxidative stress in hypothyroid patients. Int J Endocrinol Metab. 2004; 2(2): 103-9.

45. Purice M, Ursu I, Baicus C, Goldstein A, Niculescu D. Hyperhomocysteinemia in moderate and severe hypothyroidism. Acta Endocrinologica (Buc). 2010; 6(4): 431-42.

46. Sütken E, Akalin A, Ozdemir F, Colak O. Lipid profile and levels of homocysteine, leptin, fibrinogen and $C$-reactive protein in hyperthyroid patients before and after treatment. Dicle Medical Journal. 2010; 37(1):1-7.

47. Gunduz M, Gunduz E, Kircelli F, Okur N, Ozkaya M. Role of Surrogate Markers of Atherosclerosis in Clinical and Subclinical Thyroidism. International Journal of Endocrinology. 2012; 2012. doi: 10.1155/2012/109797.

48. Neves C, Esteves C, Pereira M, Palmares C, Sokhatsha O, Dias C, et al. Subclinical autoimmune thyroid disease and cardiovascular risk factors. Endocrinol Metab (Seoul). 2015; 30(3): 246-251. doi: 10.3803/EnM.2015.30.3.246.
49. Zoccolella S, Tortorella C, Iaffaldano P, Direnzo V, D'Onghia M, Paolicelli D, et al. Elevated plasma homocysteine levels in patients with multiple sclerosis are associated with male gender. Journal of neurology. 2012; 259(10): 2105-10.

50. Kocer B, Engur S, Ak F, Y1lmaz M. Serum vitamin B12, folate, and homocysteine levels and their association with clinical and electrophysiological parameters in multiple sclerosis. Journal of Clinical Neuroscience. 2009; 16(3): 399-403.

51. Sabry H.M, Selim H. A, Goda T. Serum Total Homocysteine and Its Biomarkers "Vitamin B 12 and Folic Acid" In Patients with Multiple Sclerosis: The Relation to Disease Course, Severity and Cognitive Impairment. Egypt J Neurol Psychiat Neurosurg. 2010; 47(1): 169-174.

52. Salemi G, Gueli MC, Vitale F, Battaglieri F, Guglielmini E, Ragonese P, et al. Blood lipids, homocysteine, stress factors, and vitamins in clinically stable multiple sclerosis patients. Lipids Health Dis. 2010; 9:19. doi: 10.1186/1476-511X-9-19.

53. Triantafyllou N, Evangelopoulos M-E, Kimiskidis VK, Kararizou E, Boufidou F, Fountoulakis KN, et al. Increased plasma homocysteine levels in patients with multiple sclerosis and depression. Ann Gen Psychiatry. 2008 Sep 9;7:17. doi: 10.1186/1744-859X-7-17.

54. Watanabe H, Suganuma N, Hayashi A, Hirowatari Y, Hirowatari T, Ohsawa M. No relation between folate and homocysteine levels and depression in early pregnant women. Bioscience trends. 2010; 4(6): 344-50.

55. Forti P, Rietti E, Pisacane N, Olivelli V, Dalmonte E, Mecocci $\mathrm{P}$, et al. Blood homocysteine and risk of depression in the elderly. Arch Gerontol Geriatr. 2010; 51(1): 21-5. doi: 10.1016/j.archger.2009.06.009.

56. Almeida OP, McCaul K, Hankey GJ, Norman P, Jamrozik K, Flicker L. Homocysteine and depression in later life. Arch Gen Psychiatry. 2008 Nov;65(11):128694. doi: 10.1001/archpsyc.65.11.1286.

57. Pascoe MC, Crewther SG, Carey LM, Noonan K, Crewther DP, Linden T. Homocysteine as a potential biochemical marker for depression in elderly stroke survivors. Food Nutr Res. 2012; 56. doi: 10.3402/fnr.v56i0.14973.

58. Alexopoulos P, Topalidis S, Irmisch G, Prehn K, Jung $\mathrm{S}$, Poppe $\mathrm{K}$, et al. Homocysteine and cognitive function in geriatric depression. Neuropsychobiology. 2010; 61(2): 97-104.

59. Tu M-C, Huang C-W, Chen N-C, Chang W-N, Lui $\mathrm{C}-\mathrm{C}$, Chen $\mathrm{C}-\mathrm{F}$, et al. Hyperhomocysteinemia in Alzheimer dementia patients and cognitive decline after 6 months follow-up period. Acta Neurol Taiwan. 2010; 19(3): 164-73.

60. Saczynski JS, Beiser A, Seshadri S, Auerbach S, Wolf $\mathrm{P}, \mathrm{Au} \mathrm{R}$. Depressive symptoms and risk of dementia The Framingham Heart Study. Neurology. 2010; 75(1): 35-41. doi: 10.1212/WNL.0b013e3181e62138.

61. Li L, Cao D, Desmond R, Rahman A, Lah JJ, Levey $\mathrm{AI}$, et al. Cognitive performance and plasma levels of homocysteine, vitamin B12, folate and lipids in patients with Alzheimer disease. Dementia and geriatric cognitive disorders. 2008; 26(4): 384-90. 
62. Weiner MF, de la Plata CM, Fields BJ, Womack KB, Rosenberg RN, Gong Y-H, et al. Brain MRI, apoliprotein E genotype, and plasma homocysteine in American Indian Alzheimer disease patients and Indian controls. Current Alzheimer Research. 2009; 6(1): 52-8.

63. Rajagopalan P, Hua X, Toga AW, Jack Jr CR, Weiner MW, Thompson PM. Homocysteine effects on brain volumes mapped in 732 elderly individuals. Neuroreport. 2011; 22(8): 391-5. doi: 10.1097/WNR.0b013e328346bf85.

64. Fei X, Hongxiang Z, Qi C, Daozhen C. Maternal plasma levels of endothelial dysfunction mediators including AM, CGRP, sICAM-1 and tHcy in preeclampsia. Adv Clin Exp Med. 2011; 21(5): 573-9.

65. Javadi EHS, Ghorbali F, Sarookhani M, Javadi A, Mashrabi $\mathrm{O}$. The relationship between the level of homocysteine in mother's serum and the intensity of preeclampsia. Life Science Journal. 2012; 9(4): 12471249.

66. Mahdavian M, Shojaeian Z, Abbasian M, Tabatabeechehr M. Folic Acid concentration and its relation with blood Hemocysteine level in women with and without Preeclampsia. Journal of North Khorasan University of Medical Sc. 2011; 3(1): 79-84.

67. Laskowska M, Oleszczuk J. Homocysteine in pregnancies complicated by preeclampsia with and without IUGR: a comparison with normotensive pregnant women with isolated IUGR and healthy pregnant women. Open Journal of Obstetrics and Gynecology. 2011; 1(4): 191-196. DOI: 10.4236/ojog.2011.14037.

68. Khosrowbeygi A, Ahmadvand H. Serum levels of oxidative stress biomarkers in preeclampsia. Yafteh. 2012; 14(3): 5-13.

69. Rahimi G, Tazakori Z, Shateri N. Relation between Homocysteine serum levels and pregnancy complicated with preeclampsia occurrence. Journal of Ardabil University of Medical Sciences (JAUMS). 2010; 10(36): 121-127.

70. Mao D, Che J, Li K, Han S, Yue Q, Zhu L, et al. Association of homocysteine, asymmetric dimethylarginine, and nitric oxide with preeclampsia. Archives of gynecology and obstetrics. 2010; 282(4): 371-5.
71. Mujawar SA, Patil VW, Daver RG. Study of serum homocysteine, folic acid and vitamin B12 in patients with preeclampsia. Indian Journal of Clinical Biochemistry. 2011; 26(3): 257-60.

72. El-Motayam AS, El-Safy E, Hussien AG. Plasma Homocysteine, S100B Levels and Cognitive Impairment in Parkinson Patients. Clin Chem Lab Med. 2005; 43(10): 1107-10.

73. Lee PH, Kim H-S, Lee JE, Choi Y, Hong JY, Nam HS, et al. Comparison of endothelial progenitor cells in Parkinson's disease patients treated with levodopa and levodopa/COMT inhibitor. PloS one. 2011; 6(6): e21536.

74. Zhang L, Yan J, Xu Y, Long L, Zhu C, Chen X, et al. The Combination of Homocysteine and C-Reactive Protein Predicts the Outcomes of Chinese Patients with Parkinson's Disease and Vascular Parkinsonism. J Neural Transm (Vienna). 2011; 118(9): 1329-33. doi: 10.1007/s00702-011-0614-9.

75. Nevrly M, Kanovsky P, Vranova H, Langova K, Hlustik P. Effect of entacapone on plasma homocysteine levels in Parkinson's disease patients. Neurological sciences. 2010; 31(5): 565-9.

76. Müller T, Jugel C, Ehret R, Ebersbach G, Bengel G, Muhlack S, et al. Elevation of total homocysteine levels in patients with Parkinson's disease treated with duodenal levodopa/carbidopa gel. J Neural Transm (Vienna). 2011; 118(9): 1329-33. doi: 10.1007/s00702011-0614-9.

77. Isobe C, Abe T, Terayama Y. L-Dopa therapy increases homocysteine concentration in cerebrospinal fluid from patients with Parkinson's disease. Journal of Clinical Neuroscience. 2010; 17(6): 717-21.

78. Mojiminiyi O, Marouf R, Al Shayeb A, Qurtom M, Abdella N, Al Wazzan $\mathrm{H}$, et al. Determinants and Associations of Homocysteine and Prothrombotic Risk Factors in Kuwaiti Patients with Cerebrovascular Accident. Med Princ Pract. 2008; 17(2): 136-42. doi: 10.1159/000112968.

79. Trabetti E. Homocysteine, MTHFR gene polymorphisms, and cardio-cerebrovascular risk. J Appl Genet. 2008;49(3):267-82. doi: 10.1007/BF03195624.

80. Koch w, Ndrepepa G, Mehilli J, Braun S, Burghartz $\mathrm{M}$, Lengnick $\mathrm{H}$, et al. Homocysteine Status and Polymorphisms of Methylenetetrahydrofolate Reductase Are Not Associated With Restenosis After Stenting in Coronary Arteries. Arterioscler Thromb Vasc Biol. 2003; 23(12): 2229-2234. 